\title{
Metabolism of 3-Nitrotyrosine Induces Apoptotic Death in Dopaminergic Cells
}

\author{
Béatrice Blanchard-Fillion, ${ }^{1}$ Delphine Prou, ${ }^{2}$ Manuela Polydoro, ${ }^{1}$ David Spielberg, ${ }^{1}$ Elpida Tsika, ${ }^{1}$ Zeneng Wang, ${ }^{5}$ \\ Stanley L. Hazen, ${ }^{5}$ Michael Koval, ${ }^{6}$ Serge Przedborski, ${ }^{2,3,4}$ and Harry Ischiropoulos ${ }^{1,7}$ \\ ${ }^{1}$ Stokes Research Institute, Children's Hospital of Philadelphia, Philadelphia, Pennsylvania 19104, Departments of ${ }^{2}$ Neurology and ${ }^{3}$ Pathology and Cell \\ Biology and ${ }^{4}$ Center of Neurobiology and Behavior, Columbia University, New York, New York 10032, ${ }^{5}$ Department of Cardiovascular Medicine and Center \\ for Cardiovascular Diagnostics and Prevention, Cleveland Clinic Foundation, Cleveland, Ohio 44195, and Departments of ${ }^{6} \mathrm{Physiology}$ and ${ }^{7} \mathrm{Pharmacology}$, \\ University of Pennsylvania, Philadelphia, Pennsylvania 19104
}

Intrastriatal injection of 3-nitrotyrosine, which is a biomarker for nitrating oxidants, provokes dopaminergic neuronal death in rats by unknown mechanisms. Herein, we show that extracellular 3-nitrotyrosine is transported via the L-aromatic amino acid transporter in nondopaminergic NT2 cells, whereas in dopaminergic PC12 cells, it is transported by both the l-aromatic amino acid and the dopamine transporters. In both cell lines, 3 -nitrotyrosine is a substrate for tyrosine tubulin ligase, resulting in its incorporation into the $\mathrm{C}$ terminus of $\alpha$-tubulin. In NT2 cells, incorporation of 3-nitrotyrosine into $\alpha$-tubulin induces a progressive, reversible reorganization of the microtubule architecture. In PC12 cells, 3-nitrotyrosine decreases intracellular dopamine levels and is metabolized by the concerted action of the aromatic amino acid decarboxylase and monoamine oxidase. Intracellular levels of $133 \mu$ mol of 3-nitrotyrosine per mole of tyrosine did not alter NT2 viability but induced PC12 apoptosis. The cell death was reversed by caspases and aromatic amino acid decarboxylase and monoamine oxidase inhibitors. 3-Nitrotyrosine induced loss of tyrosine hydroxylase-positive primary rat neurons, which was also prevented by an aromatic amino acid decarboxylase inhibitor. These findings provide a novel mechanism by which products generated by reactive nitrogen species induce dopaminergic neuron death and thus may contribute to the selective neurodegeneration in Parkinson's disease.

Key words: dopamine; neurotoxicity; aromatic amino acid decarboxylase; monoamine oxidase; reactive nitrogen species; nitration; tubulin

\section{Introduction}

Reactive nitrogen species are thought to play a pathogenic role in a variety of neurodegenerative diseases, such as Parkinson's disease (PD) (Ischiropoulos and Beckman, 2003). This view stems in part from the demonstrations that proteins, such as $\alpha$-synuclein and parkin, are posttranslationally modified by reactive nitrogen species in the brains of PD patients (Giasson et al., 2000; Chung et al., 2004). A fingerprint of reactive nitrogen species formation is 3-nitrotyrosine, which results from the reaction of nitrating oxidants with either protein tyrosine residues or free tyrosine (Ischiropoulos, 1998). Therefore, detection and quantification of 3-nitrotyrosine has been used as an indicator for the participation of reactive nitrogen species in pathological processes (Ohshima et al., 1990; Greenacre and Ischiropoulos, 2001; Turko and Murad,

Received Nov. 8, 2005; accepted April 6, 2006.

The work was supported by National Institutes of Health (NIH) Grant HL076491 (S.L.H.), Department of Defense DAMD Grants 17-99-1-9474 and 17-03-1-0002, and Morris K. Udall Parkinson's Disease Research Center of Excellence Grant NS38370 (S.P.), and NIH Grants HL54926 and AG13966 (H.I.). We thank Xiaoming Fu for mass spectrometric analysis, Dr. L. Lafanechere (Commissariat à l'Energie Atomique, Grenoble, France) for the generous gift of the anti-Glu-tubulin antibody, and R. Lightfoot for helpful discussions.

Correspondence should be addressed to Dr. Harry Ischiropoulos, Stokes Research Institute, Children's Hospital of Philadelphia, 416D Abramson Research Center, 34th Street and Civic Center Boulevard, Philadelphia, PA 191044399. E-mail: ischirop@mail.med.upenn.edu.

DOI:10.1523/JNEUROSCI.1038-06.2006

Copyright $\odot 2006$ Society for Neuroscience $\quad$ 0270-6474/06/266124-07\$15.00/0
2002). In that context, it is worth noting that nitrated proteins, as well as free 3-nitrotyrosine, have also been detected and quantified in rodent models of neurodegeneration and PD. Injection of 1-methyl-4-phenyl-1,2,3,6-tetrahydropyridine was associated with levels of $300 \mu \mathrm{mol}$ of 3-nitrotyrosine per mole of tyrosine in mouse striatum (Pennathur et al., 1999). Challenges with other neurotoxic agents, such as malonate or 3-nitropropionic acid, resulted in nearly $5 \mathrm{mmol}$ of 3-nitroyrosine per mole of tyrosine (Schulz et al., 1995). The significant increases in 3-nitrotyrosine in these models were diminished by the application of nitric oxide synthesis inhibitors (Schulz et al., 1995) and were absent if neuronal nitric oxide synthase-deficient mice were challenged with the same neurotoxins (Pennathur et al., 1999).

Although free 3-nitrotyrosine has been considered as a biological marker for reactive nitrogen species formation, recent data suggest that this unusual amino acid is also a potential neurotoxin. For instance, striatal injection of free 3-nitrotyrosine at concentrations similar to 6-hydroxydopamine, which causes a well described degenerative pathology and a parkinsonian syndrome in rats, induced a selective loss of dopaminergic neurons (Mihm et al., 2001). Although these data suggest that dopaminergic neurons are particularly sensitive to 3-nitrotyrosine, the molecular basis of 3-nitrotyrosine deleterious effects is unknown. Also unclear is how 3-nitrotyrosine gains access to dopaminergic 
neurons and, once inside these neurons, whether toxicity is mediated by 3-nitrotyrosine itself or possibly by other 3-nitrotyrosine metabolites. To address these questions, we investigated the uptake and metabolism of 3-nitrotyrosine in both the dopamine-producing PC12 and the nondopamineproducing NT2 cell lines as well as in primary ventral midbrain rat neurons. Although the formation of reactive nitrogen species is considered as the major biochemical event responsible for neuron death, the present study suggests that longer-lived products of the nitrative chemistry are also neurotoxic to dopaminergic neurons.

\section{Materials and Methods}

Materials. Tyrosine, 3-nitrotyrosine, 2-aminobicyclo-(2,2,1)-heptane-2carboxylic acid (BCH), pargyline, NSD1015 (3-hydroxybenzylhydrazine dihydrochloride), GBR12935 (1-[2-(diphenyl-methoxy)-ethyl]-4-(3phenylpropyl)piperazine), and tyramine oxidase were purchased from Sigma (St. Louis, MO). The holoenzyme tyrosine (aromatic amino acid) decarboxylase from Streptococcus faecalis was purchased from Worthington (Freehold, NJ).

Cell culture. The experiments were performed with the undifferentiated human teratocarcinoma NT2 and rat pheochromocytoma PC12 cell lines. NT2 cells were cultured in Optimem medium supplemented with $10 \%$ fetal bovine serum and $1 \%$ penicillin-streptomycin (containing 100 $\mu \mathrm{M}$ tyrosine). PC12 cells were cultured in RPMI-1640 medium supplemented with $10 \%$ heat-inactivated horse serum, $5 \%$ fetal calf serum, 5 $\mathrm{mm}$ L-glutamine, and $1 \%$ penicillin-streptomycin. The medium was refreshed every $2-3 \mathrm{~d}$. For all experiments, PC12 cells were plated on collagencoated surface for $48 \mathrm{~h}$ before additional treatment or until cells reached $60 \%$ confluence. Both cell lines were maintained at $37^{\circ} \mathrm{C}$ in $5 \% \mathrm{CO}_{2}$.

Cell treatment. NT2 or PC12 cells (50-60\% confluent) were treated with a range of 3-nitrotyrosine concentrations for 24,48 , or $72 \mathrm{~h}$, in the presence or absence of several inhibitors. Chemical compounds used were the L-aromatic amino acid transporter inhibitor $\mathrm{BCH}$ (at a final concentration of $100 \mu \mathrm{M}$ ), the monoamine oxidase inhibitor pargyline $(100 \mu \mathrm{M})$, the aromatic amino acid decarboxylase inhibitor NSD1015 $(100 \mu \mathrm{M})$, the dopamine transporter inhibitor GBR12935 (10 $\mu \mathrm{M})$, the caspase-1 inhibitor benzyloxycarbonyl-Try-Val-Ala-Asp-chloromethylketone (Ac-YVAD-CMK) (50 $\mu \mathrm{M}$; Alexis Biochemicals, San Diego, CA), the caspase-3 inhibitor Z-Asp-Glu-Val-fluoromethyl ketone (Z-DEVDFMK) (50 $\mu \mathrm{M}$; BD PharMingen, San Jose, CA), and the general caspases inhibitor $\mathrm{N}$-benzyloxycarbonyl-Val-Ala-Asp-fluoromethyl ketone (ZVAD-FMK) (50 $\mu \mathrm{M}$; BD PharMingen, San Jose, CA). Cells were pretreated with cysteine (final concentration of $1 \mathrm{~mm}$ ) or the inhibitors for $18 \mathrm{~h}$ before 3-nitrotyrosine treatment and re-added every $24 \mathrm{~h}$.

Measurement of cell death with trypan blue exclusion method. Cell viability during the treatment with 3-nitrotyrosine in the presence or absence of inhibitors was monitored using the trypan blue exclusion method. Numbers of alive and dead cells were determined using a hemocytometer under a light microscope. Healthy nuclei from viable cells appeared round and phase bright, whereas nuclei from dead or dying cells appeared blue and irregularly shaped. In all experiments, floating cells were collected and assayed using the procedure and criteria described above. All cells were counted, and results were expressed as ratio of dead cells versus total cells (alive + dead).

Annexin $V$ and flow cytometry. For apoptosis or necrosis detection, cells were stained with fluorescein isothiocyanate-labeled annexin $\mathrm{V}$ and propidium iodide (PI) (Vybrant apoptosis assay kit; Invitrogen, Carlsbad, CA). After incubations, floating as well as adherent cells that were later trypsinized were pooled and centrifuged for $5 \mathrm{~min}$ at $1400 \mathrm{rpm}$. Pelleted cells were washed with PBS, centrifuged again, and resuspended in $100 \mu \mathrm{l}$ of $1 \times$ annexin-binding buffer (10 mM HEPES, $140 \mathrm{~mm} \mathrm{NaCl}$, and $2.5 \mathrm{mM} \mathrm{CaCl}_{2}, \mathrm{pH} 7.4$ ) yielding a cell density of $2 \times 10^{6}$ cells $/ \mathrm{ml}$. A total of $10 \mu \mathrm{l}$ of annexin V conjugate and $2 \mu \mathrm{l}$ of $100 \mu \mathrm{g} / \mathrm{ml}$ PI working reagent were added to each $100 \mu \mathrm{l}$ of cell suspension. The cells were incubated at room temperature for $30 \mathrm{~min}$. After the incubation period, $400 \mu \mathrm{l}$ of $1 \times$ annexin-binding buffer was added and the samples were kept on ice. The stained cells were analyzed by flow cytometry, and the percentage of cells was calculated using the Cellquest software. This method was able to distinguish among living (annexin $\mathrm{V}^{-} / \mathrm{PI}^{-}$), apoptotic (annexin $\mathrm{V}^{+} / \mathrm{PI}^{-}$), and necrotic (annexin $\mathrm{V}^{-} / \mathrm{PI}^{+}$) cells.

Postnatal rat midbrain cell culture model. Midbrain cultures obtained as described previously (Przedborski et al., 1996) were maintained 2 weeks at $37^{\circ} \mathrm{C}$ in $5 \% \mathrm{CO}_{2}$, and then wells were randomly assigned to either treatment group or to the control group. 3-Nitrotyrosine or 3-nitrotyramine was added to the culture medium at a final concentration of 2 and $1 \mathrm{~mm}$, respectively, for $70 \mathrm{~h}$. Separate wells were pretreated for $24 \mathrm{~h}$ with $400 \mu \mathrm{M}$ NSD1015 or $500 \mu \mathrm{M}$ pargyline before treatment with 3-nitrotyrosine. Control cultures received PBS instead of 3 -nitrotyrosine, and NSD 1015 was re-added every $24 \mathrm{~h}$. At the end of the treatment, the medium was aspirated and cultures were fixed in $0.1 \mathrm{~m}$ PBS containing $4 \%$ paraformaldehyde for $30 \mathrm{~min}$ at $4^{\circ} \mathrm{C}$. After four washes with PBS, the cells were incubated in $0.1 \%$ Triton X-100 in PBS plus $5 \%$ normal goat serum for $1 \mathrm{~h}$. The cells were then incubated overnight at $4{ }^{\circ} \mathrm{C}$ with a mouse monoclonal anti-tyrosine hydroxylase antibody (1:800; Chemicon, Temecula, CA) in PBS containing 0.1\% Triton X-100 and 3\% normal goat serum. After four washes in PBS, cells were incubated with an Alexa-Fluor 488 secondary antibody (goat antimouse, 1:500; Invitrogen) in PBS containing 0.1\% Triton X-100 and 3\% normal goat serum for $1 \mathrm{~h}$. Cultures were then rinsed four times in PBS, and coverslips were mounted on slides using DakoCytomation (Glostrup, Denmark) fluorescent mounting medium. Only cells with distinct immunoreactivity, clear neuronal shape, and a nucleus were considered for counting tyrosine hydroxylase-positive neurons.

Western blotting. Cells were washed with PBS, solubilized in $100 \mu \mathrm{l}$ of ice-cold lysis buffer [20 mM HEPES, $150 \mathrm{~mm} \mathrm{NaCl}, 1 \mathrm{~mm}$ EGTA, $1.5 \mathrm{~mm}$ $\mathrm{MgCl}_{2}, 10 \%$ glycerol, $1 \%$ Triton X-100, protease inhibitors (1 mM phenylmethylsulfonyl fluoride, $1 \mu \mathrm{g} / \mathrm{ml}$ aprotinin, $1 \mu \mathrm{g} / \mathrm{ml}$ leupeptin, $10 \mathrm{~mm}$ sodium pyrophosphate, and $50 \mathrm{~mm}$ sodium fluoride), $2 \mathrm{~mm}$ sodium orthovanadate, and $1 \mu \mathrm{m}$ lactacystin), sonicated, and analyzed by Western blotting. The protein concentration was determined by a Bradford assay. Proteins ( $40 \mu \mathrm{g})$ were separated by a 10\% SDS-page gel transferred overnight to polyvinylidene difluoride or nitrocellulose membranes at 20 $\mathrm{V}$ and probed with an affinity-purified polyclonal anti-3-nitrotyrosine antibody (1:5000 dilution) (Fries et al., 2003), a monoclonal anti- $\alpha$ tubulin antibody (1:3000 dilution; clone B-5-1-2; Sigma), and a monoclonal anti-glyceraldehyde-3-phosphate dehydrogenase (GAPDH) antibody (1:40,000 dilution; Chemicon). HRP-conjugated goat anti-rabbit IgG or HRP-conjugated goat anti-mouse IgG (1:5000 dilution) (BioRad, Hercules, CA) was used for detection. Proteins were then visualized by enhanced chemiluminescence. For band quantification, fluorescent secondary antibodies were used suitable for the infrared imaging system, membranes were scanned, and fluorescence was measured (1:7500 dilution; Odyssey; LI-COR Biosciences, Lincoln, NE).

Immunofluorescence microscopy. Cells were fixed with cold methanol for $20 \mathrm{~min}$ at $-20^{\circ} \mathrm{C}$ and a mixture of cold acetone/methanol at $1: 1$ for 5 min at $-20^{\circ} \mathrm{C}$. The cells were blocked in PBS plus $0.3 \%$ Triton $\mathrm{X}-100$ (PBS-T) containing $10 \% \mathrm{BSA}$ and normal goat serum for $1 \mathrm{~h}$ at $25^{\circ} \mathrm{C}$. After several washes with PBS-T, the cells were double labeled with polyclonal anti-3-nitrotyrosine (1:300) and monoclonal anti- $\alpha$-tubulin (1: 1000) antibodies left overnight at $4^{\circ} \mathrm{C}$. Secondary antibodies were indocarbocyanine-conjugated goat anti-rabbit IgG (1:250 dilution; Jackson ImmunoResearch, West Grove, PA) and Alexa-Fluor 488conjugated goat anti-mouse IgG (1:500 dilution; Invitrogen). Nuclear counterstaining was performed by using 4' -6-diamidino-2-phenylindole (1:10,000 dilution; Invitrogen). Fluorescent images were obtained using an inverted microscope 1X70 (Olympus Optical, Tokyo, Japan) or by confocal immunofluorescence microscopy.

Tyrosine decarboxylase activity assay. Tyrosine decarboxylase activity was quantified by measuring the conversion of tyrosine to tyramine by HPLC. Tyrosine $(0.4 \mathrm{~mm})$ diluted in $0.1 \mathrm{~m}$ sodium acetate buffer at $\mathrm{pH}$ 5.5 , the reported optimal $\mathrm{pH}$ for the catalytic activity of tyrosine decarboxylase (Epps, 1944), was incubated at $37^{\circ} \mathrm{C}$ with tyrosine decarboxylase $(0.25 \mathrm{U} / \mathrm{ml})$, in the absence or presence of different concentrations of 3 -nitrotyrosine. Aliquots of the reaction mixture were taken over time, acidified to stop the enzymatic reaction, centrifuged at 10,000 rpm for 5 min, and then analyzed by HPLC equipped with a diode array detector. 
Tyramine oxidase activity assay. Tyramine oxidase activity was quantified by measuring the conversion of tyramine to 4-hydroxybenzaldehyde by HPLC. To obtain pure 3-nitrotyramine, 3-nitrotyrosine (1.5 $\mathrm{mm})$ was incubated with $0.25 \mathrm{U} / \mathrm{ml}$ tyrosine decarboxylase at $37^{\circ} \mathrm{C}$ in $0.1 \mathrm{M}$ sodium acetate buffer, $\mathrm{pH}$ 5.5 , for $5 \mathrm{~h}$. After acidification and centrifugation, the reaction mixture was analyzed by HPLC showing the formation of a single product presenting an absorbance at $365 \mathrm{~nm}$. The identity of the nitrated derivative formed was confirmed by mass spectrometry as 3nitrotyramine (mass/charge ratio of 183).

The reported optimal $\mathrm{pH}$ for the reaction of tyramine oxidase is 7.0 (Yamada et al., 1967). Tyramine $(0.4 \mathrm{~mm})$ diluted in $0.1 \mathrm{~m}$ sodium acetate at $\mathrm{pH} 6.9$ was incubated at $37^{\circ} \mathrm{C}$ with tyramine oxidase $(0.25 \mathrm{U} / \mathrm{ml})$ in the absence or presence of different concentrations of 3 -nitrotyramine. Aliquots were removed ( 80 $\mu l$ ) over time, acidified (addition of $8 \mu \mathrm{l}$ of $1 \mathrm{~N}$ $\mathrm{HCl})$ to stop the enzymatic reaction, centrifuged at 10,000 rpm for $5 \mathrm{~min}$, and then analyzed by HPLC.

HPLC detection of tyrosine and nitrotyrosine metabolites. Aliquots of reaction mixtures were analyzed by a Hewlett Packard (Palo Alto, CA) HPLC system with a diode array detector using an octadodecyl silica gel reverse-phase column, $5 \mu \mathrm{m}, 4.6 \times 250 \mathrm{~mm}$ (Jupiter; Phenomenex, Torrance, CA) and $0.1 \%$ trifluoroacetic acid in ultra pure water (solvent $\mathrm{A}$ ) and $100 \%$ acetonitrile (solvent $\mathrm{B}$ ). The reaction mixture was eluting using an increasing linear gradient of solvent $\mathrm{B}$ from 0 to $15 \%$ in $10 \mathrm{~min}$ and then to $17 \%$ in $25 \mathrm{~min}$, at a flow rate of $1 \mathrm{ml} / \mathrm{min}$. The HPLC detector was set at 215, 275 , and $365 \mathrm{~nm}$. The HPLC system was calibrated with external standards at 275 and $365 \mathrm{~nm}$ to follow the nitrated products. Under these HPLC conditions, tyrosine, tyramine, 3-nitrotyrosine, 3-nitrotyramine, 4-hydroxybenzaldehyde, and 4-hydroxy-3-nitro-benzaldehyde were eluted at 11.1, 10.6, 14.1, 15, 13.6, and $22.2 \mathrm{~min}$, respectively. Kinetic parameters were determined by Lineweaver-Burk plots of initial velocities obtained with a substrate concentration of $0.4 \mathrm{~mm}$ tyrosine and tyramine for tyrosine decarboxylase and tyramine oxidase, respectively.

HPLC detection of dopamine metabolites. PC12 cells were lysed in mobile phase (citrate/phosphate buffer containing 2\% methanol, pH 3), sonicated, and centrifuged. Supernatants were further centrifuged on $0.22 \mu \mathrm{m}$ filter Eppendorf, preequilibrated with mobile phase. Fifty microliter aliquots were analyzed by HPLC with electrochemical detection set at $-200,0,200,300$, and $400 \mathrm{~V}$ (Coularray; ESA, Chelmsford, MA). Chromatographic separation was achieved using an octadodecyl silica gel reverse-phase column, $5 \mu \mathrm{m}, 4.6 \times 250 \mathrm{~mm}$ (Jupiter; Phenomenex), providing complete separation of all analytes of interest, including, in order of elution, L-3,4-dihydroxyphenylalanine (1-DOPA), dopamine, and 3,4-dihydroxyphenylacetic acid (DOPAC). The residual pellets were resuspended in lysis buffer and sonicated, and protein concentrations were determined.

Quantification of 3-nitrotyrosine by HPLC-tandem mass spectrometry. Control and 3-nitrotyrosine treated cells were washed extensively with ice-cold PBS and harvested after application of trypsin in PBS. Cells were sonicated, and the content of free and protein 3-nitrotyrosine in lysates was analyzed by HPLC with on-line electrospray ionization tandem mass spectrometry (LC/ESI/MS/MS) using stable isotope dilution methodology on a triple quadrupole mass spectrometer (API 365; Applied Biosystems, Foster City, CA) with Ionics EP $10+$ upgrade (Ionics, Concord, Ontario, CA) interfaced to a Cohesive Technologies (Franklin, MA) Aria LX Series HPLC multiplexing system, as described in detail previously (Brennan et al., 2002). Synthetic $\left[{ }^{13} \mathrm{C}_{6}\right]$-labeled standard was used as in- ternal standard for quantification of natural abundance 3-nitrotyrosine. Simultaneously, a universal labeled precursor amino acid, $\left[{ }^{13} \mathrm{C}_{9},{ }^{15} \mathrm{~N}_{1}\right]$ tyrosine, was added, permitting potential intrapreparative formation of nitro $\left[{ }^{13} \mathrm{C}_{9},{ }^{15} \mathrm{~N}\right]$ tyrosine to be routinely monitored and shown to be negligible (i.e., $\ll 5 \%$ of the level of the natural abundance product observed). Results are normalized to the content of the precursor amino acid tyrosine (i.e., nitrotyrosine/tyrosine, micromoles/moles), which was monitored within the same injection.

\section{Results \\ Incorporation of 3-nitrotyrosine into tubulin in NT2 and \\ PC12 cells}

Undifferentiated NT2 and PC12 cells were incubated with 250 and $500 \mu \mathrm{M} 3$-nitrotyrosine (i.e., 2.5- and 5-fold excess over tyrosine) for $48 \mathrm{~h}$. Probing the cell extracts with an affinity-purified anti-3-nitrotyrosine antibody revealed a single nitrated protein, which comigrated with $\alpha$-tubulin and whose abundance increased as a function of 3-nitrotyrosine concentration (Fig. $1 A, B)$. To confirm that the protein was indeed $\alpha$-tubulin, NT2 cell lysates were immunoprecipitated with a monoclonal anti- $\alpha$ tubulin antibody. The immunoprecipitated $\alpha$-tubulin did react with an anti- $\alpha$-tubulin or an anti-3-nitrotyrosine antibody (Fig. $1 C)$. Densitometric analysis using fluorescent secondary antibodies showed that 8 and $15 \%$ of total $\alpha$-tubulin was nitrated. Thus, during exposure of NT2 and PC12 cells to 3-nitrotyrosine, a fraction of $\alpha$-tubulin incorporates this modified amino acid.

Treatment of NT2 cells with 3-nitrotyrosine in the presence of $\mathrm{BCH}$, an inhibitor of the L-aromatic amino acid transporter (Christensen et al., 1969), significantly decreased the incorporation of 3-nitrotyrosine to $\alpha$-tubulin (Fig. 1). Moreover, the uptake of 3-nitrotyrosine competed with the transport of tyrosine. 


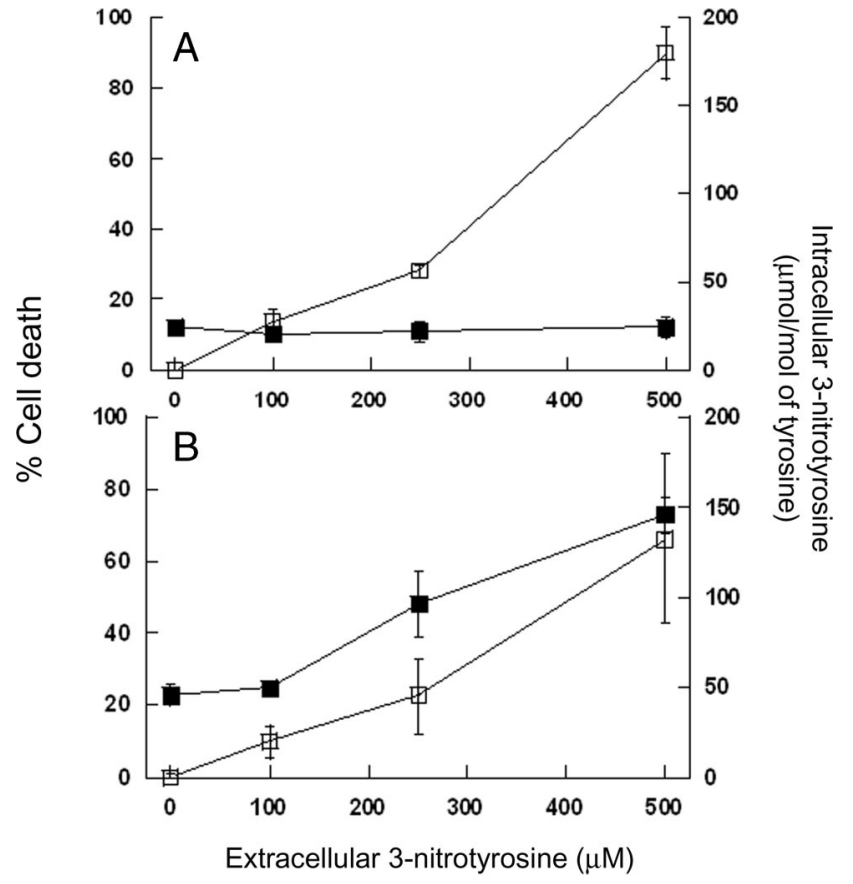

Figure 2. Cytotoxicity induced by 3-nitrotyrosine in PC12 and NT2 cells. $A$, NT2 cells were treated with a range of 3-nitrotyrosine concentrations for $72 \mathrm{~h}$. The percentage of cell death ( $\square$ ) was measured with trypan blue exclusion (left axis), and intracellular concentrations of 3-nitrotyrosine $(\square)$ were quantified by LC/ECI/MS/MS and expressed as picomoles of 3-nitrotyrosine per mole of tyrosine (right axis) as described in Materials and Methods. $\boldsymbol{B}$, The same treatment and quantification were performed $\mathrm{PC} 12$ cells. The values represent mean \pm SD of three independent determinations. ${ }^{*} p<0.05$, ANOVA with Tukey's post hoc analysis.

In the absence of 3-nitrotyrosine, the levels of extracellular tyrosine declined by $23 \pm 2$ and $42 \pm 3 \%$ after 48 and $72 \mathrm{~h}$, respectively. However, in the presence of $500 \mu \mathrm{M} 3$-nitrotyrosine, the extracellular tyrosine levels declined by only $15 \pm 1$ and $20 \pm 2 \%$ after 48 and $72 \mathrm{~h}$. These data indicate that the uptake of 3-nitrotyrosine in NT2 cells involves the L-aromatic amino acid transporter and competes with the transport of tyrosine.

\section{Effect of 3-nitrotyrosine on NT2 and PC12 cell viability}

Incubation of NT2 and PC12 cells for $48 \mathrm{~h}$ with extracellular concentrations of 3-nitrotyrosine, ranging from 0 to $500 \mu \mathrm{M}$, produced a dose-dependent increase in intracellular levels of 3 -nitrotyrosine in both cell lines (Fig. $2 A, B$ ). The increase in the intracellular 3-nitrotyrosine levels were not associated with any detectable death in the noncatecholaminergic NT2 cells based on trypan blue exclusion and propidium iodide and annexin $\mathrm{V}$ with flow cytometry assays (Fig. 2). In contrast, catecholaminergic PC12 cells showed a significant increase in cell death, which was proportional to the intracellular levels of 3-nitrotyrosine (Fig. $2 B)$. By flow cytometry, $46 \pm 3$ and $65 \pm 5 \%$ of the PC12 cells were positive for annexin $\mathrm{V}$ when the intracellular levels of 3 -nitrotyrosine reached mean values of 45 and $133 \mu \mathrm{mol} / \mathrm{mol}$ tyrosine, respectively (Fig. 2 B). The death of PC12 cells induced by 3-nitrotyrosine was prevented by pretreatment with caspase-1, caspase-3, or pan-caspase inhibitors (Fig. 3) but not by the antioxidant cysteine (Fig. 3). These results suggest that cytotoxicity induced by 3-nitrotyrosine in PC12 cells involves in part activation of apoptosis but does not rely on oxidation events.

Pretreatment of PC12 with the L-aromatic amino acid transporter inhibitor $\mathrm{BCH}$ resulted in a marginal inhibition of cell death (Fig. 3). Under the same conditions, pretreatment of PC12

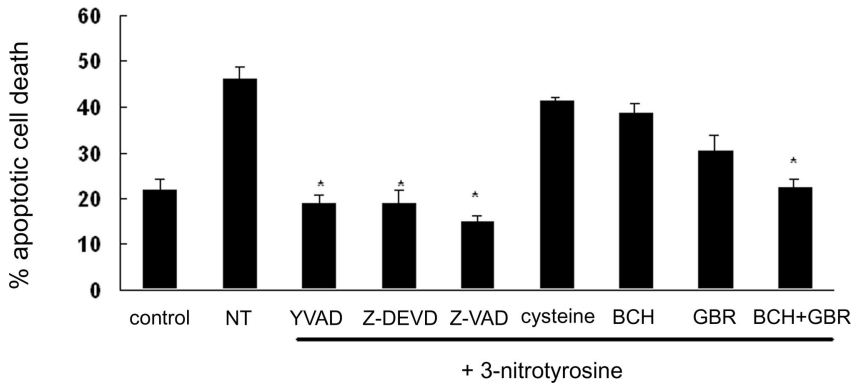

Figure 3. 3-Nitrotyrosine induced apoptosis in $\mathrm{PC} 12$ cells. Apoptotic $\mathrm{PC} 12$ cell death was evaluated by flow cytometry using annexin $\mathrm{V}$ and propidium iodide labeling in control untreated cells and cells with intracellular levels of $133 \pm 47 \mu \mathrm{mol}$ of 3-nitrotyrosine (NT) per moles of tyrosine. Addition of the caspase-1 inhibitor (AC-YVAD-CMK, $50 \mu \mathrm{M}$ ), the caspase-3 inhibitor (Z-DEVD-FMK, $50 \mu \mathrm{m}$ ), and the general caspase inhibitor (Z-VAD-FMK, $50 \mu \mathrm{M}$ ) during incubation with 3-nitrotyrosine prevented apoptotic cell death. Pretreatment of cells with 1 $\mathrm{mm}$ cysteine, $100 \mu \mathrm{M} \mathrm{BCH}$, or $10 \mu \mathrm{m}$ of the dopamine transporter inhibitor GBR12935 did not prevent apoptotic cell death. Pretreatment of PC12 cells for $18 \mathrm{~h}$ with both $100 \mu \mathrm{m} \mathrm{BCH}$ plus 10 $\mu \mathrm{M}$ GBR12935 inhibited the 3-nitrotyrosine-induced apoptotic cell death. The values represent mean \pm SD for $n=3-6$ independent determinations. ${ }^{*} p<0.05$ difference from 3 -nitrotyrosine-treated group by ANOVA with Tukey's post hoc analysis.

with the dopamine transporter inhibitor GBR12935 resulted in a $56 \pm 2 \%$ reduction in the intracellular 3-nitrotyrosine levels and in a $15 \%$ decline in cell death (Fig. 3). By combining both $\mathrm{BCH}$ and GBR12935 pretreatments, the magnitude of cell death was comparable with controls (Fig. 3). We thus conclude that both the L-aromatic amino acid and dopamine transporters mediate the uptake of 3-nitrotyrosine in PC12 cells.

\section{Incorporation of 3-nitrotyrosine into $\alpha$-tubulin disrupts} microtubule morphology in a reversible manner in NT2 cells In contrast to PC12 cells, intracellular 3-nirotyrosine did not compromise cell viability in NT2 cells. However, the incorporation of 3-nitrotyrosine in the $\mathrm{C}$ terminus of $\alpha$-tubulin resulted in the progressive disruption of the normal architecture of microtubules, as revealed by confocal immunofluorescence microscopy (Fig. 4). Although some filamentous microtubules were visualized in cells with intracellular levels of $56 \mu \mathrm{mol}$ of 3 -nitrotyrosine per mole of tyrosine (Fig. $4 \mathrm{~B}$ ), none were observed after the intracellular levels reached $180 \mu \mathrm{mol}$ of 3-nitrotyrosine per mole of tyrosine (Fig. 4C). Instead, cells contained numerous well defined $\alpha$-tubulin-positive, rounded structures resembling aggregates, which were located primarily in the cytosol (Fig. 4C). These aberrant $\alpha$-tubulin-positive structures were not immunoreactive for either lysosome-associated membrane protein-1 or ubiquitin, suggesting that these structures are not targeted for degradation by the lysosomal or proteasomal pathway (data not shown). Treatment of NT2 with 3 -nitrotyrosine for $24 \mathrm{~h}$ in the presence of nocodozole, a microtubule destabilizing agent (Gundersen et al., 1984), prevented the incorporation of 3-nitrotyrosine into $\alpha$-tubulin (Fig. 4D). Nocodozole sequesters $\alpha$-tubulin dimers and forms an inactive complex that renders the $\alpha$-tubulin dimers incapable of incorporating either tyrosine or 3-nitrotyrosine by tyrosine tubulin ligase.

To determine whether incorporation of 3-nitrotyrosine into $\alpha$-tubulin was reversible, cells were cultured for $48 \mathrm{~h}$ with 3 -nitrotyrosine-supplemented medium and then in medium without 3-nitrotyrosine for 2-24 h. Already after $2 \mathrm{~h}$ incubation in fresh medium, a decrease in 3-nitrotyrosine-labeled $\alpha$-tubulin and a concomitant increase in glutamate (Glu)-tubulin was de- 
tectable (supplemental Fig. 1, available at www.jneurosci.org as supplemental material). Immunoblotting and immunofluorescence showed that nitrotyrosinated $\alpha$-tubulin was no longer detectable after $24 \mathrm{~h}$ of incubation in fresh medium, and the normal filamentous architecture of microtubules was restored. Inhibition of protein synthesis using cycloheximide did not prevent the disappearance of nitrated $\alpha$-tubulin. Moreover, the total level of $\alpha$-tubulin did not change over the time course of this experiment, and Glu-tubulin levels remained comparable with control levels after $24 \mathrm{~h}$ incubation in fresh medium (supplemental Fig. 1, available at www.jneurosci.org as supplemental material). These data suggest that the loss of nitrotyrosinated $\alpha$-tubulin is attributable to a removal of the modified amino acid by tubulin carboxypeptidase and not to a turnover of the modified protein.

\section{Effect of 3-nitrotyrosine on dopamine biosynthesis and metabolism in PC12 cells}

3-Nitrotyrosine does not interfere with the activity of tyrosine hydroxylase in PC12 cells (Ischiropoulos et al., 1995). However, like dopamine, 3-nitrotyrosine is modified in one of the two equivalent ortho carbons of the aromatic ring of tyrosine, suggesting that it may be substrate for the aromatic amino acid decarboxylase. Consistent with this view, incubation of PC12 cells with $100 \mu \mathrm{M} 3$-nitrotyrosine for $72 \mathrm{~h}$ led to a concentration-dependent increase in intracellular 1-DOPA and DOPAC levels (Table 1). The effect of 3-nitrotyrosine on catechol levels was compared with the effect of NSD1015, an inhibitor of the aromatic amino acid decarboxylase, and of pargyline, a monoamine oxidase inhibitor. Treatment with NSD1015 abolished dopamine and DOPAC and raised the intracellular levels of L-DOPA by nearly ninefold compared with control (Table 1). Treatment with pargyline did not affect 1-DOPA levels, increased dopamine levels, and prevented DOPAC formation (Table 1). These results indicated that, similar to NSD1015, 3-nitrotyrosine interferes with the activity of aromatic amino acid decarboxylase but not tyrosine hydroxylase, which is consistent with previous results (Ischiropoulos et al., 1995). However, unlike NSD1015, the levels of DOPAC were increased in 3-nitrotyrosine-treated cells, indicating that 3nitrotyrosine also interferes with the activity of monoamine oxidase.

Using purified aromatic amino acid decarboxylase and monoamine oxidase, we confirmed that the aromatic amino acid decarboxylase converted 3-nitrotyrosine to 3-nitrotyramine and monoamine oxidase converted 3-nitrotyramine to 3-nitro-4-

C

D
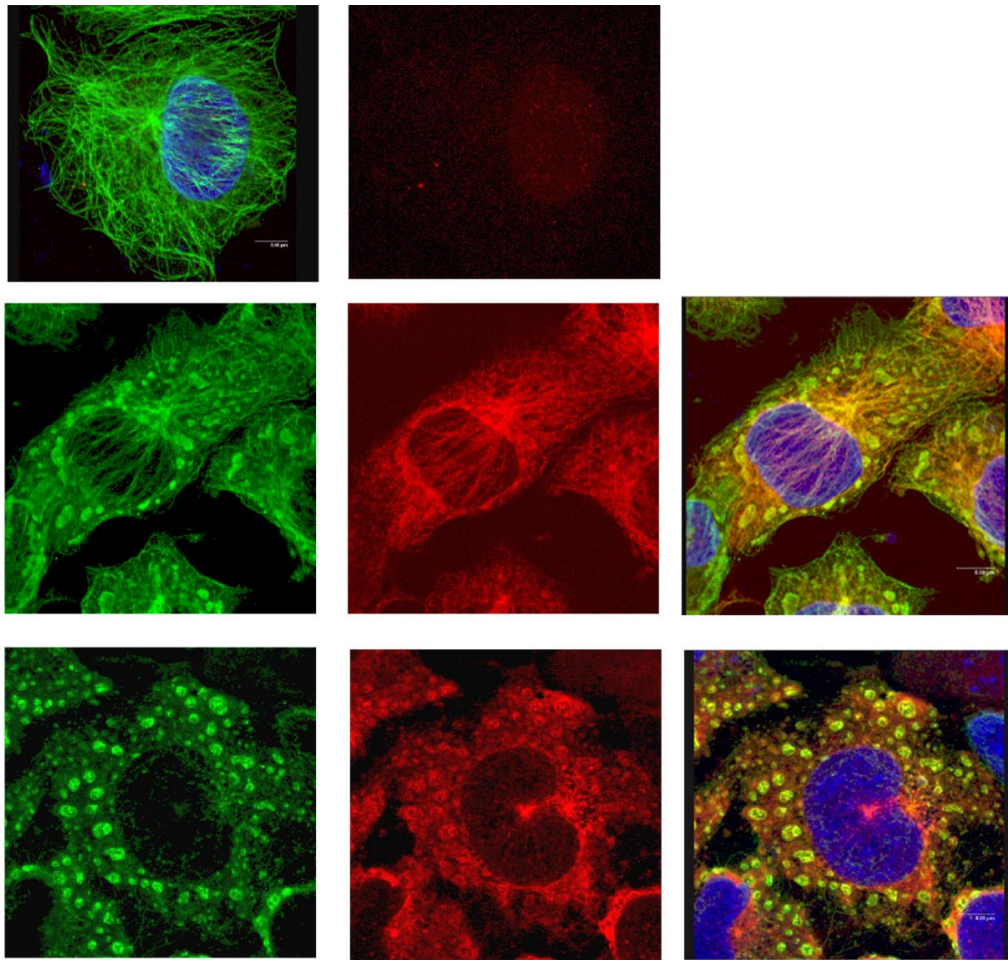

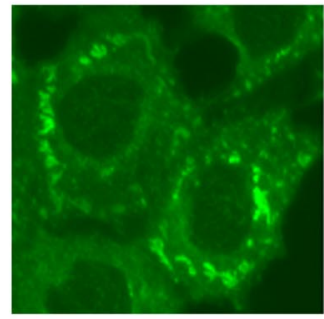

anti $\alpha$-tubulin

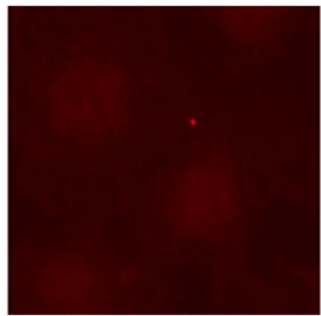

anti 3-nitrotyrosine

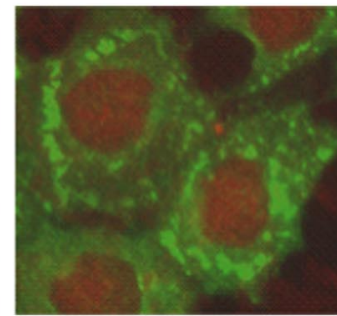

merged
Figure 4. Incorporation of 3-nitrotyrosine to $\alpha$-tubulin monomers is mediated by tyrosine tubulin ligase and disrupts the microtubule architecture in the NT2 cells. Undifferentiated NT2 cells were either untreated $(\boldsymbol{A})$ or treated with 2.5 -fold $(\boldsymbol{B})$ and fivefold $(\boldsymbol{C})$ excess 3-nitrotyrosine over tyrosine for $24 \mathrm{~h}$, and confocal imaging of the cells are depicted using anti- $\alpha$-tubulin (green) and anti-3-nitrotyrosine (red) antibodies. Cells pretreated with $5 \mu \mathrm{m}$ nocodozole or previous incubation with $250 \mu \mathrm{m}$ 3-nitrotyrosine for $24 \mathrm{~h}(\boldsymbol{D})$ did not incorporate 3-nitrotyrosine into $\alpha$-tubulin.

Table 1. Interference of 3-nitrotyrosine on dopamine production and metabolism

\begin{tabular}{|c|c|c|c|}
\hline & $\begin{array}{l}\text { L-DOPA (pmol/ } \mu \mathrm{g} \\
\text { protein) }\end{array}$ & $\begin{array}{l}\text { Dopamine (pmol/ } \\
\mu g \text { protein) }\end{array}$ & $\begin{array}{l}\text { DOPAC (pmol/ } \\
\mu g \text { protein) }\end{array}$ \\
\hline Control & $0.06 \pm 0.01$ & $27.76 \pm 2.08$ & $0.37 \pm 0.02$ \\
\hline \multicolumn{4}{|l|}{$20 \pm 9 \mu \mathrm{mol} 3$-nitrotyrosine } \\
\hline /mol tyrosine & $0.12 \pm 0.02^{*}$ & $27.81 \pm 0.51$ & $0.54 \pm 0.05^{*}$ \\
\hline $45 \pm 21 \mu \mathrm{mol}$ 3-nitrotyrosine/mol tyrosine & $0.25 \pm 0.02^{*}$ & $15.69 \pm 2.18^{*}$ & $0.71 \pm 0.06^{*}$ \\
\hline $133 \pm 47 \mu \mathrm{mol} 3$-nitrotyrosine/mol tyrosine & $0.52 \pm 0.08^{*}$ & $13.25 \pm 2.83^{*}$ & $0.65 \pm 0.15^{*}$ \\
\hline NSD1015 & $0.53 \pm 0.04^{*}$ & 0 & 0 \\
\hline Pargyline & $0.05 \pm 0.01$ & $40.81 \pm 2.8^{*}$ & 0 \\
\hline
\end{tabular}

PC12 cells were treated with 3-nitrotyrosine for $72 \mathrm{hr}$, which resulted in different intracellular concentrations measured by LC/ESI/MS/MS with $0.1 \mathrm{~mm}$ NSD1015 or with $0.1 \mathrm{~mm}$ pargyline, and intracellular levels of L-DOPA, dopamine, and DOPAC were quantified after chromatographic separation and electrochemical detection. The levels are expressed as picomoles of analyte per microgram of protein $(n=3)$. The area under the peak was used to determine analyte levels using a seven-point concentration curve of internal standards. ${ }^{*} p<0.05$, ANOVA with Tukey's post hoc analysis.

hydroxyphenylacetate (supplemental Fig. 2, available at www. jneurosci.org as supplemental material). This indicated that 3-nitrotyrosine is not only an inhibitor of aromatic amino acid decarboxylase and monoamine oxidase but also a substrate. Moreover, tyrosine was a noncompetitive inhibitor for the conversion of 3-nitrotyrosine to 3-nitrotyramine by aromatic amino 

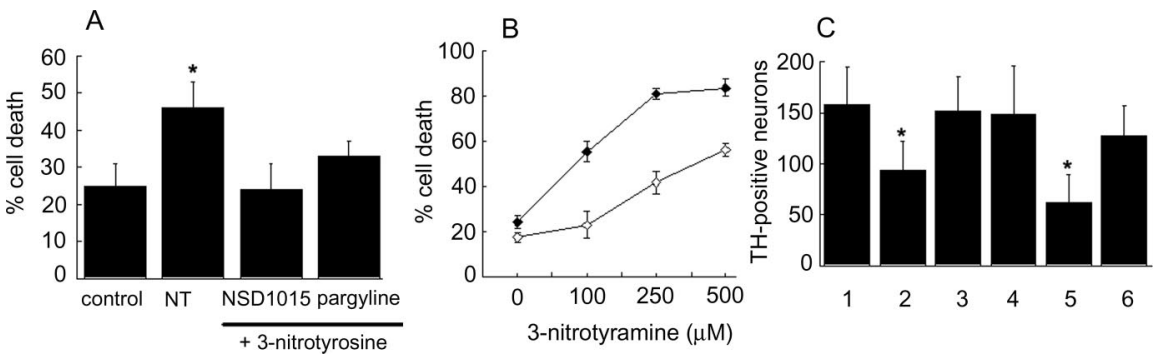

Figure 5. Metabolism of 3-nitroyrosine required for cell death. $A$, Preincubation of PC12 cells with either NSD105 or pargyline reduced $\mathrm{PC} 12$ cell death to control levels. The values represent mean \pm SD, $n=5-6 ;{ }^{*} p<0.05$, ANOVA with Tukey's post hoc analysis. NT, 3-Nitrotyrosine. $\boldsymbol{B}, \mathrm{PC} 12$ cells were treated with a range of 3-nitrotyramine concentrations for $24 \mathrm{~h}$ in the absence $(\diamond)$ or presence of $0.1 \mathrm{~mm}$ pargyline $(\diamond)$. Cell death was evaluated with trypan blue exclusion. 3-Nitrotyramine was synthesized as described in Materials and Methods, and purity was verified by HPLC-MS. The values represent mean $\pm S D, n=3 ;{ }^{*} p<0.05$, Student's $t$ test. C, 1, Tyrosine hydroxylase-positive neurons under control conditions; $2,72 \mathrm{~h}$ after treatment with 3-nitrotyrosine; 3, pretreatment with NDS1015 before 3-nitrotyrosine exposure; 4, tyrosine hydroxylase-positive neurons under control conditions; $5,72 \mathrm{~h}$ after treatment with 3-nitrotyramine; 6 , pretreatment with pargyline before3-nitrotyramine exposure. The values represent mean $\pm S D$, $n=12-15$ separate wells from two independent cultures. ${ }^{*} p<0.05$, ANOVA with Tukey's post hoc analysis.

acid decarboxylase, whereas tyramine, a natural substrate of monoamine oxidase, was an uncompetitive inhibitor for the conversion of 3-nitrotyramine to 3-nitro-4-hydroxyphenylacetate (supplemental Fig. 2, available at www.jneurosci.org as supplemental material). In addition, after exposure to 3-nitrotyrosine for $48 \mathrm{~h}, 0.6 \mathrm{pmol}$ of 3-nitro-4-hydroxyphenylacetate was detected by LC/ESI/MS/MS in PC12 cell lysates. These data support the observed inhibition of dopamine production and indicated that 3-nitrotyrosine was metabolized by the aromatic amino acid decarboxylase and monoamine oxidase to 3-nitro-4hydroxyphenylacetate. Although 3-nitro-4-hydroxyphenylacetate has the potential for additional cytotoxicity, it is not a substrate for tubulin tyrosine ligase and thus did not incorporate into $\alpha$-tubulin (Eiserich et al., 1999).

\section{Metabolism of 3-nitrotyrosine to 3-nitro-4- hydroxyphenylacetate leads to death of PC12 cells and primary rat midbrain neurons}

Pretreatment with NSD1015 or pargyline before 3-nitrotyrosine incubation reduced the level of PC12 cell death to control levels (Fig. 5). To assess whether the metabolism of 3-nitrotyrosine is neurotoxic to primary dopaminergic neurons, rat ventral midbrain cultures were exposed to 3-nitrotyrosine for $72 \mathrm{~h}$. This incubation resulted in a significant $41 \%$ reduction in tyrosine hydroxylase-positive neurons (Fig. 6). Similarly, as in PC12 cells, 3 -nitrotyrosine-associated cell death in ventral midbrain neurons was prevented by a pretreatment with NSD1015 (Fig. 6). Incubation of PC12 cells and rat ventral midbrain neurons with 3-nitrotyramine also led to cell death in both culture systems (Fig. $6 B, C)$. The toxicity of 3-nitortyramine was prevented by pargyline (Fig. $6 B, C$ ). These results suggest that cell death was linked to the metabolism of 3-nitrotyrosine by the aromatic amino acid decarboxylase and monoamine oxidase.

\section{Discussion}

Free 3-nitrotyrosine is formed in vivo by the reaction of tyrosine with nitrating oxidants and potentially by the degradation of nitrated proteins by the proteasome or other proteolytic enzymes (Souza et al., 2000). Until recently, the detection of free 3 -nitrotyrosine under physiological or pathological conditions has been considered as a marker of oxidative and nitrative stress (Ohshima et al., 1990; Greenacre and Ischiropoulos, 2001; Turko and Murad, 2002). However, the data presented herein indicate that 3-nitrotyrosine at intracellular levels comparable with levels measured in the brain (Schulz et al., 1995; Pennathur et al., 1999) can be a cell-specific neurotoxin. The neurotoxicity of 3 -nitrotyrosine is linked to its enzymatic conversion via the concerted action of the aromatic amino acid decarboxylase to 3-nitro4-phenylacetate.

The finding that 3-nitrotyrosine is metabolized to a neurotoxic metabolite provides a novel biochemical pathway that explains the neurotoxic effects of direct 3-nitrotyrosine injection into rat striatum. Striatal injections of 3-nitrotyrosine at relative high concentrations ( $8 \mathrm{~mm}$ ) produced selective loss of dopaminergic neurons, primarily attributable to apoptotic cell death, without any apparent incorporation into striatal proteins (Mihm et al., 2001).3-Nitrotyrosine was also capable of inducing apoptosis in rat motor neurons without any apparent nitrotyrosination of tubulin but failed to induce astrocyte death in which incorporation of 3-nitrotyrosine into $\alpha$-tubulin was observed (Peluffo et al., 2004). Although the molecular mechanisms for the neurotoxicity of 3-nitrotyrosine in motor neurons are not known at present, collectively these results indicate that a product of nitrative stress causes neurotoxicity in neuronal cells that is not related to its incorporation to $\alpha$-tubulin.

Incorporation of 3-nitrotyrosine into $\alpha$-tubulin had a profound but reversible effect on the organization of microtubules in NT2 cells without any detrimental effect on cellular viability. The incorporation of 3-nitrotyrosine into $\alpha$-tubulin is the only recognized pathway for incorporation of 3-nitrotyrosine into proteins because other studies have confirmed that 3-nitrotyrosine does not incorporated to the tRNA pool of amino acids and, as such, will not be incorporated into newly synthesized proteins (Greene, 1971; Ischiropoulos et al., 1995). The lack of a toxic effect of tubulin nitrotyrosination is consistent with previous reports in other cell types, which also indicated a reversible incorporation without a significant effect on viability (Bisig et al., 2002). We extended these observations by providing evidence that the reversible incorporation into $\alpha$-tubulin was attributable to the tubulin decarboxylase. Although the incorporation into $\alpha$-tubulin does not compromise cellular viability, it alters vascular permeability and myogenic differentiation (Eiserich et al., 1999; Chang et al., 2002). Moreover, systemic administration of 3-nitrotyrosine to rodents resulted in the induction of hypothyroidism by inhibiting the function of the thyroid tyrosine deiodinase (Greene, 1971), modulated vascular hemodynamic responses to angiotensin II by acting as an $\alpha, \beta$-adrenoreceptor antagonist (Kooy and Lewis, 1996), and caused vascular endothelial dysfunction (Mihm et al., 2000).

Collectively, the data suggest a new paradigm for the oxidative stress-mediated neurotoxicity. Presently, it has been suggested that deregulated overproduction of reactive species accompanied by a decline in the antioxidant defenses permits the destruction of neuronal macromolecules and results in the demise of neurons (Beal, 2002; Dawson and Dawson, 2003; Dauer and Przedborski, 2003; Ischiropoulos and Beckman, 2003). However, unless the reactive species are produced continuously, they are incapable of sustaining pressure onto cells over long periods of time. In contrast to the highly reactive oxygen and nitrogen species, relatively 
more stable products such as 3-nitrotyrosine can sustain a toxic effect over longer periods of time because metabolism to nonoxidizing metabolites is required for toxicity. These metabolites might have more subtle, long-lived and cell-specific cytotoxicity than the more generalized oxidant damage by reactive oxygen and nitrogen species. Therefore, 3-nitrotyrosine and possibly other unusual amino acids need to be considered in the biochemical and molecular mechanisms of neurotoxicity in addition to oxidant damage imposed by reactive nitrogen species.

\section{References}

Beal MF (2002) Oxidatively modified proteins in aging and disease. Free Radic Biol Med 32:797-803.

Bisig CG, Purro SA, Contin MA, Barra HS, Arce CA (2002) Incorporation of 3 -nitrotyrosine into the $\mathrm{C}$-terminus of a-tubulin is reversible and not detrimental to dividing cells. Eur J Biochem 269:5037-5045.

Brennan ML, Wu W, Fu X, Shen Z, Song W, Frost H, Vadseth C, Narine L, Lenkiewicz E, Bochers MT, Lusis AJ, Lee JJ, Lee NA, Abu-Soud HM, Ischiropoulos H, Hazen SL (2002) A tale of two controversies: defining both the role of peroxidases in nitrotyrosine formation in vivo using eosinophil peroxidase and myeloperoxidase-deficient mice, and the nature of peroxidasegenerated reactive nitrogen species. J Biol Chem 277:17415-17427.

Chang W, Webster DR, Salam AA, Gruber D, Prasad A, Eiserich JP, Bulinski JC (2002) Alteration of tubulin's C-terminal amino acid specifically inhibits myogenic differentiation. J Biol Chem 277:30690-30698.

Christensen HN, Handlogten ME, Lam I, Tager HS, Zand R (1969) A bicyclic amino acid to improve discriminations among transport systems. J Biol Chem 244:1510-1520.

Chung KK, Thomas B, Li X, Pletnikova O, Troncoso JC, Marsh L, Dawson VL, Dawson TM (2004) S-Nitrosylation of parkin regulates ubiquitination and compromises Parkin's protective function. Science 304:1328-1331.

Dauer W, Przedborski S (2003) Parkinson's disease: mechanisms and models. Neuron 39:889-909.

Dawson TM, Dawson VL (2003) Molecular pathways of neurodegeneration in Parkinson's disease. Science 302:819-822.

Eiserich JP, Estevez AG, Bamberg TV, Ye YZ, Chumley PH, Beckman JS, Freeman BA (1999) Microtubule dysfunction by posttranslational nitrotyrosination of $\alpha$-tubulin: a nitric oxide-dependent mechanism of cellular injury. Proc Natl Acad Sci USA 96:6365-6370.

Epps H (1944) Studies on bacterial amino-acid decarboxylases. Tyrosine decarboxylase from Streptococcus faecalis. Biochem J 38:242.

Fries DM, Paxinou E, Themistocleous M, Swanberg E, Griendling KK, Salvemini D, Slot JW, Heijnen HFG. Hazen SL, Ischiropoulos H (2003) Expression of inducible nitric oxide synthase and intracellular protein tyrosine nitration in vascular smooth muscle cells: role of reactive oxygen species. J Biol Chem 278:22901-22907.

Giasson BI, Duda JE, Murray IV, Chen Q, Souza JM, Hurtig HI, Ischiropoulos H, Trojanowski JQ, Lee VM (2000) Oxidative damage linked to neurodegeneration by selective alpha-synuclein nitration in synucleinopathy lesions. Science 290:985-989.
Greenacre SAB, Ischiropoulos H (2001) Tyrosine nitration: localisation, quantification, consequences for protein function and signal transduction. Free Radic Res 34:541-581.

Greene WL (1971) Effects of 3-nitro-L-tyrosine on thyroid function in the rat: an experimental model for the dehalogenase defect. J Clin Invest 50:2474-2484.

Gundersen GG, Kalnoski MH, Bulinski JC (1984) Distinct population of microtubules: tyrosinated and nontyrosinated alpha tubulin are distributed differently in vivo. Cell 38:779-789.

Ischiropoulos H (1998) Biological tyrosine nitration: a pathophysiological function of nitric oxide and reactive oxygen species. Arch Biochem Biophys 356:1-11.

Ischiropoulos H, Beckman JS (2003) Oxidative stress and nitration in neurodegeneration: cause, effect or association? J Clin Invest 111:163-169.

Ischiropoulos H, Duran D, Horwitz J (1995) Peroxynitrite-mediated inhibition of DOPA synthesis in PC12 cells. J Neurochem 65:2366-2372.

Kooy NW, Lewis SJ (1996) The peroxynitrite product 3-nitro-L-tyrosine attenuates the hemodynamic responses to angiotensin II in vivo. Eur J Pharmacol 315:165-170.

Mihm MJ, Jing L, Bauer JA (2000) Nitrotyrosine causes selective vascular endothelial dysfunction and DNA damage. J Cardiovasc Pharmacol 36:182-187.

Mihm MJ, Schanbacher BL, Wallace BL, Wallace LJ, Uretsky NJ, Bauer JA (2001) Free 3-nitrotyrosine causes striatal neurodegeneration in vivo. J Neurosci 21:1-5.

Ohshima H, Friesen M, Brouet I, Bartsch H (1990) Nitrotyrosine as a new marker for endogenous nitrosation and nitration of proteins. Food Chem Toxicol 28:647-652.

Peluffo H, Shacka JJ, Ricart K, Bisig G, Martinez-Palma L, Pritsch O, Kamaid A, Eiserich JP, Crow JP, Barbeito L, Estevez AG (2004) Induction of motor neuron apoptosis by free 3-nitro-L-tyrosine. J Neurochem 89:602-612.

Pennathur S, Jackson-Lewis V, Przedborski S, Heinecke JW (1999) Mass spectrometric quantification of 3-nitrotyrosine, ortho-tyrosine, and o, $\mathrm{o}^{\prime}$ dityrosine in brain tissue of 1-methyl-4-phenyl-1,2,3,6-tetrahydropyridine-treated mice, a model of oxidative stress in Parkinson's disease. J Biol Chem 274:34621-34628.

Przedborski S, Khan U, Kostic V, Carlso E, Epstein CJ, Sulzer D (1996) Increased superoxide dismutase activity improves survival of cultured postnatal midbrain neurons. J Neurochem 67:1383-1392.

Schulz JB, Matthews RT, Jenkins BG, Ferrante RJ, Siwek D, Henshaw DR, Cipolloni PB, Mecocci P, Kowall NW, Rosen BR, Beal MF (1995) Blockade of neuronal nitric oxide synthase protects against excitotoxicity in vivo. J Neurosci 15:8419-8429.

Souza JM, Choi I, Chen Q, Weisse M, Daikhin E, Yudkoff M, Obin M, Ara J, Horwitz J, Ischiropoulos H (2000) Proteolytic degradation of tyrosine nitrated proteins. Arch Biochem Biophys 380:360-366.

Turko IV, Murad F (2002) Protein nitration in cardiovascular diseases. Pharmacol Rev 54:619-634.

Yamada H, Kumagai H, Kawasaki H, Matsui H, Ogata K (1967) Crystallization and properties of diamine oxidase from pig kidney. Biochem Biophys Res Commun 29:723-727. 